Titih Huriah¹, Nurul Hidayah², Akichika Mikami ${ }^{3}$

${ }^{1}$ Master of Nursing, Universitas Muhammadiyah Yogyakarta, Indonesia ${ }^{2}$ School of Nursing, Universitas Muhammadiyah Yogyakarta, Indonesia ${ }^{3}$ Faculty of Nursing and Rehabilitation, Chubu

Gakuin University, Japan

Corresponding Author: Titih Huriah Email: titih.huriah@umy.ac.id

\section{Attitudes and Associated Factors towards Care for Dying Patients among Non-Palliative Care Nurses, Yogyakarta, Indonesia}

\begin{tabular}{ll}
\hline Article Info & \\
Online & $:$ http://journal.umy.ac.id/index.php/ijnp \\
ISSN & $: 25484249$ (Print) \\
& $: 2548$ 592X (Online) \\
DOI & \\
Article History & \\
Received & $: 03$ October 2020 \\
Revised & $: 01$ March 2021 \\
Accepted & $: 01$ March 2021
\end{tabular}
hospitals, five primary health centers, and three nursing homes in Yogyakarta. Systematic random sampling was the method employed. The research instrument used Frommelt Attitudes towards Care of the Dying (FATCOD). FATCOD is a 30-item tool using a five-point Likert scale to indicate respondents' attitudes toward caring for dying patients. Attitudes had two categories, namely favorable ( $\geq$ mean score of the total score of (FATCOD) Scale) and unfavorable $<$ mean score of the total score of (FATCOD) Scale). Two hundred seventeen (217) non-palliative care nurses completed the FATCOD and a tenitem demographic questionnaire. The data analysis used descriptive statistics, chi-square, and linear regression.

Results: The total FATCOD score achieved in this study was 111.29 \pm 9.44 (range 30-150). Concerning nurses' attitudes towards the family members of terminally ill dying patients, the score was 39.85 ( \pm 4.12 ) out of a possible 50. Besides attitudes towards patient care provision, the score was $71.43( \pm 6.39)$ out of a possible 100 . The nurses' attitudes towards the dying patients showed that the favorable and unfavorable attitudes had almost the same percentage. Of significance, working experience variables were associated with attitudes in the total FATCOD and patient FATCOD. Working experience and level of education were related to attitudes towards the family FATCOD.

Conclusion: Non-palliative care nurses had a favorable attitude towards palliative care. The ministry of health should give awareness by providing various training, workshop, formal and informal education about $P C$ for nurses.

Keywords: attitude, nurses, palliative care, Yogyakarta, FATCOD, death and dying 


\section{NONRSERSING \\ PRACTICES}

\section{INTRODUCTION}

The challenges for palliative care in South-East Asia have been identified as limited palliative care services, lack of understanding and negative perceptions about palliative care, constraints on available resources, poor symptom management, and late referrals (Wright et al., 2008). Leong (2003) stated that World Palliative Care Alliance (WPCA) mapped Indonesia's palliative care services in the third category, which means the isolated palliative care with the development of palliative care was not well supported and was limited in number compared to the size of the population. There are severe deficits in this field in many countries. The need for PCs will further increase due to demographic developments with growing numbers of older people with incurable chronic diseases and multiple morbidities (Kassa et al., 2014).

The UN has predicted that the percentage of Indonesians over 60 years will reach 25 percent by 2050 or nearly 74 million older people. Several provinces have a higher number of older people than the national average, and Yogyakarta has the nation's largest elderly population (Mahendradhata, 2017). Based on a review of palliative care services in Yogyakarta, only one health institution was provided with palliative care services. Also, the haste to develop palliative care units has resulted in many services being run by doctors and nurses with limited knowledge and understanding of palliative care (Leong, 2003). This limitation causes several problems when providing palliative care to patients.

Staff who provide end-of-life care are more likely to experience high levels of emotional exhaustion (McConnel, 2017; Namasivayam et al., 2013; Yang et al., 2017). Many report feelings of emotional distress, anxiety, and a lack of preparation to provide care to patients at the end of life and their families. It has been reported that end-of-life care is one of the most common sources of stress for nurses. A study found that $91 \%$ of nurses were unsure how to react when patients talked about death and dying. Some nurses may choose to avoid discussing emotional issues with patients, and some may decide not to tell the truth about the patient's condition. The differences in reactions may be attributed to personal attitudes to death, experiences, understanding of end-of-life care, and others. The factors will finally shape the care provided, whether the nurses are aware of it. Understanding the factors that affect nurses' attitudes will help develop strategies and resources they need to use to cope with stressful situations (Yang et al., 2017).

The palliative care service is successfully delivered through the combined effect of knowledge, attitudes, beliefs, and healthcare providers' experiences (Al Qadire, 2014). Nurses' feeling of poor preparation and stress contributes to nurses exacerbating negative attitudes toward death and caring for the dying patients that may further impact the standard of care (Wang et al., 2016). To provide quality care at the end of life or for chronically ill patients, nurses must have a good attitude about palliative care to meet patients' and their families' needs adequately (Kassa et al., 2014; Lewis et al., 2016). Traditionally, high-quality care at the end of life has mainly been provided for cancer patients in inpatient hospices. Still, this kind of care needs to be provided for those with a broader range of diseases.

Countries need to develop health care services to meet the medical and social needs of palliative care. An effective care must reach the hospital, people's homes and nursing, and residential homes within the community. The role of care staff during the period near the end of life is essential. The attitudes of non-palliative nurses about terminal care, life, and death were surveyed to clarify the present status and future assignment of palliative care in these countries.

\section{METHODS}

A cross-sectional study was conducted with nurses at hospitals, primary health centers, and nursing homes in Yogyakarta from January 2020 to June 2020. This study was confined to nurses working in a governmental hospital (1 hospital), nongovernmental hospitals ( 3 hospitals), five primary health centers, and three nursing homes. The nurses serving in outpatient departments and wards of the selected hospitals were recruited to participate in the study. However, nurses working in the pediatric ward, operating room, and neonatal unit were excluded. Inclusion criteria for nurses 
who work in primary health centers and nursing homes were nurses who have provided home care palliative care.

The sample size was determined using a single population proportion formula since the total sample size was less than 10.000. Multistage sampling was applied; therefore, the initial sample size was 217 nurses. Hospitals found in Yogyakarta have been stratified into governmental and nongovernmental. Because the number of nongovernmental hospitals was more than a government hospital, a government hospital and three non-governmental hospitals were selected using simple random sampling. The same method was used for the selection of five primary health centers and three nursing homes. The number of subjects assigned was 166, 32, and 19 for the hospitals, primary health centers, and nursing homes, respectively, keeping proportionality into consideration.

The attitude scale was adopted from Frommelt Attitude Toward Care of the Dying (FATCOD) and modified to fit the Indonesian context. Validity and reliability for FATCOB Indonesian version adopted A'la (2016). The data collection instrument included two sections. Section one: A socio-demographic included (gender, institution, religion, level of education, working experience, home location, type of house, age, and family member). Section two: The Frommelt Attitude Toward Care of the Dying (FATCOD) Scale, Form B (Frommelt, 1991) is a 30item tool using a five-point Likert scale to indicate respondents' attitudes toward caring for dying patients. Scores were reversed for negative items. Possible scores can range from 30-150. A higher score indicates a more positive attitude toward caring for this patient population. Twenty items in the FATCOD scale relate directly to the nurses' attitude towards the patient (possible range 20100). Ten items pertain directly to the nurses' attitudes towards the patients' family (possible range 10-50). Data collection was conducted by four graduate nurses who received a half-day training on issues concerning the questionnaire. For qualitative data, attitudes were divided into two categories, namely favorable ( $\geq$ mean score of the total score of (FATCOD) Scale) and unfavorable (< mean score of the total score of (FATCOD) Scale).
SPSS version 16 statistical software packages analyzed the data. Descriptive analysis, student's ttest, chi-square, and linear regression were computed to summarize the data, examine the between-group differences on FATCOD scores, assess statistical association, and see the level of significance, respectively. All statistical tests were two-tailed with the alpha set at 0,05. Ethical clearance came from the Institutional Review Board (IRB) of Faculty Medicine and Health Sciences Universitas Muhammadiyah Yogyakarta. Approvals were also obtained from participating hospitals, primary health centers, and nursing homes. Verbal consent was obtained from each participant, and participants' anonymity and confidentiality were kept. The respondents had the right not to participate in or withdraw from the study at any stage.

\section{RESULTS}

A total of 217 completed questionnaires were analyzed. The research location was 12 places. There were four hospitals, three nursing homes, and five primary health centers. The majority of respondents were female (80.2\%), working in a hospital (76.5\%), and Muslim (95.4\%). The majority were from 124 (57.1\%) non-governmental hospitals for participants by their institution. 153 (70.5\%) respondents stated that their highest level of education was a diploma degree, and the majority of working experience was more than ten years (32.3\%). The majority of respondents lived in the village $(70.5 \%)$, with the type of house were own house (82.5\%). The mean age was 32.52 (SD = 7.37), with the mean of the family member was 3.94 (SD = 1.52) (See Table 1).

Based on Table 2, for nurses' attitudes towards care of the dying patients, the favorable and unfavorable attitudes have almost the same percentage.

The total FATCOD score achieved in this study was 111.29 \pm 9.44 (range 30-150). Regarding nurses' attitudes towards the family members of terminally ill dying patients, the score was $39.85( \pm 4.12)$ out of a possible 50 . Besides, concerning attitudes towards patient care provision, the score was $71.43( \pm 6.39)$ out of a possible 100 (Table 3).

The mean scores for most of the individual items in the FATCOD scale were equal to or greater than 4 (range 1-5), while the mean scores for most of the 


\section{NURCING \\ PRACTICES}

personal items in the FATCOD scale were equal to or greater than 3.

For the total FATCOD, a significant relationship between working experience and attitude towards death and dying were observed $(F=2,06 ; P=0,040)$. Similarly, for the patient-related items within the FATCOD, the working experience was a variable that

\section{DISCUSSIONS}

Nurses' attitudes towards care of dying patients show that The European Association for Palliative Care has recently described the core competencies of palliative care encompassing health professionals' abilities to meet patient's physical, social, psychological, and spiritual needs (Gamondi, 2013). Nurses' attitudes and coping skills were related to preparedness to practice in palliative care. According to the Knowledge, Attitude, and Psychomotor (KAP) theory, practice is an individual's response to stimulation. It is an actual presentation that is closely related to an individual's knowledge and attitudes. As lack of knowledge influences nursing staff's attitudes and practices toward Palliative Care Consultation Service (PCCS), education is crucial in changing these attitudes and practices. Being single was associated with positive direct effects (Pan et al., 2017).

The quality of palliative care given to terminally ill patients and their family members can be directly impacted by nurses' attitudes towards palliative care (Tait et al., 2017). Attitudes toward terminal care in nursing students were significantly correlated with communication competence $(r=0.438, P 0.001)$, spirituality $(r=0.374, P<0.001)$, and gratitude $(r=0.318, P<0.001)$. Communication competence explained $18.7 \%$ of the variance in attitudes toward terminal care (Jo, 2015).

The mean scores for most individual items in the FATCOD scale were equal to or greater than 4 (range 1-5). Meanwhile, the mean scores for most of the individual items in the FATCOD scale were equal to or greater than 3. The lowest mean score could be found at number 5 , and the statement was, "I would not want to be assigned to care for a dying person." In contrast, the highest mean score could be found at number 1 with the statement, correlated with the attitude towards death and dying, which were observed $(F=2,83 ; P=0,005)$. For the family FATCOD, a significant relationship between working experience and level of education variables were associated with attitudes towards the family FATCOD with p-value 0,037 and 0,020, respectively (see Table 3 ).

\footnotetext{
"Giving nursing care to the dying person is a worthwhile learning experience."
}

Many healthcare professionals working in general care areas did not feel confident delivering all aspects of palliative care and struggled with the communication skills required for end-of-life discussions. Nurses agreed that more could be done to help someone achieve a sense of peace at the end of life, that end of life need not be a time of great suffering and that families have the right to refuse treatment aimed at prolonging life (Monterosso et al., 2016). Attitude towards PC was influenced by awareness of death and personal characteristics (Keumhee et al., 2016).

Further analyses on other parameters showed that working experiences affected attitudes of nonpalliative care nurses in Yogyakarta. Nurses with 11-15 years of experience had the lowest professional apprehension score, while those with 21 years of experience had the highest apprehension score. The researchers investigated the association of factors, including age, sex, marital status, religion, working experience, education level, working department, post, and titles, with the attitudes toward hospice care (Yang et al., 2017). Besides, the variance analysis showed that nurses with different education levels had significantly different scores $(P, 0.05)$ on personal apprehension and overall attitude toward hospice care; the higher the education level attained, the lower the personal and professional apprehension levels (Yang et al., 2017; Kang et al., 2014). Having a master's degree had a positive, although indirect effect, on nurse practice through the influence on knowledge and attitude. It implies that nursing staff with a higher educational level would have more knowledge about PCCS, which indirectly resulted in a more favorable attitude and better practice toward palliative care to improve the provision of highquality care Pan et al., 2017; Scott et al., 2016). 
Limitations of this study are that the researchers did not do the homogeneity of the respondents, a small amount of the sample, and the uneven distribution of respondents to all health institutions in Yogyakarta.

\section{CONCLUSIONS}

Hospital nurses play a huge role in the provision of palliative nursing care. They need training on becoming a palliative nurse in hospitals, primary health centers, and nursing homes. The variables that most influenced the nurse's attitude towards dying were working experience and education level. The ministry of health should educate this problem by providing various training, workshops, and formal and informal education about PC nurses.

\section{AUTHOR CONTRIBUTION}

TH and AM designed and directed the project, worked out almost all of the activities in this research. NH performed the measurement and drafted the manuscript.

\section{CONFLICT OF INTEREST}

We have no conflict interest to declare

\section{ACKNOWLEDGEMENT}

The researchers wish to thank the nurses who have spent their valuable time participating in the study. We would also like to express our gratitude to the leaders and head administrators from the hospital, primary health center, and nursing homes for their support.

\section{REFERENCES}

A'la, M. Z. (2016). The Frommelt attitudes toward care of the dying care form $b$ (FATCOD-B) indonesia version: measurement validity using factor analysis in nursing students. Nurseline Journal, 1(1), 73-82.

https://jurnal.unej.ac.id/index.php/NL/article/ view $/ 5995$

Al Qadire, M. (2014). Knowledge of palliative care: an online survey. Nurse education today, 34(5), 714-718.

https://doi.org/10.1016/j.nedt.2013.08.019

Frommelt, K, H. (1991). The effects of death education on nurses' attitudes toward caring for terminally ill persons and their families. The American journal of hospice \& palliative care, 8(5), 37-43. https://doi.org/10.1177/104990919100800509

Gamondi, C., Larkin P., \& Payne S, A. (2013). Core competencies in palliative care: an EAPC White Paper on palliative care education part 1 . European Journal of Palliative Care, 20(2), 86145.

https://www.researchgate.net/publication/28 9310063 Core competencies in palliative ca re An EAPC white paper on palliative care education - Part 2

Jo, M, J. (2015). Factors affecting attitudes toward terminal care in nursing students. Korean $J$ Hosp Palliative Care, 18(4), 306-313.

https://doi.org/10.14475/kjhpc.2015.18.4.306

Kang, K, A., Kim, H, S., Kwon, S, H., Nam, M, J., Bang, K, S., Yu, S, J., et al. (2014). Nurses' knowledge of and attitudes toward pediatric palliative care of Korea. Korean J Hosp Palliative Care, 17(4), 289-300.

https://doi.org/10.14475/kjhpc.2014.17.4.289

Kassa, H., Murugan, R., Zewdu F, Hailu M, Woldeyohannes D. (2014). Assessment of knowledge, attitude and practice and associated factors towards palliative care among nurses working in selected hospitals, Addis Ababa, Ethiopia. BMC Palliative Care, 13(1).

https://doi.org/10.1186/1472-684X-13-6

Lewis, C., Reid, J., McLernon, Z., Ingham, R., \& Traynor, M. (2016). The impact of a simulated intervention on attitudes of undergraduate nursing and medical students towards end of life care provision. BMC Palliative Care, 15(67). https://doi.org/10.1186/s12904-016-0143-2

Leong, R, L, B. (2003). Palliative care in Malaysia: a decade of progress and going strong. Journal Pain Palliat Care Pharmacother. 17(3-4), 77-85. https://pubmed.ncbi.nlm.nih.gov/15022953/

Mahendradhata, Y., Trisnantoro, L., Listyadewi, S., Soewandono, P., Marthias, T., Harimurti, P., et al. (2017). The Republic of Indonesia Health System Review. WHO Regional Office for SouthEast Asia, 7(1). https://apps.who.int/iris/handle/10665/25471 $\underline{6}$

McConnel, T., Porter, S. (2017). The experience of providing end of life care at a children's hospice: a qualitative study. BMC Palliative Care, 16(1), 15.

https://doi.org/10.1186/s12904-017-0189-9 


\section{NUESESING \\ PRACTICES}

Monterosso, L., Ross-Adjie, G, M., Rogers, I, R, Shearer, F, M., \& Rogers, J, R. (2016). How Well Do We Understand Health Care Professionals' Perceptions and Needs in the Provision of Palliative Care? A Mixed Methods Study. Journal of Palliative Medicine, 19(7), 720-7.

https://doi.org/10.1089/ipm.2015.0421

Namasivayam, P., Lee, S., O'Connor, M., \& Barnett, T. (2013). Caring for families of the terminally ill in Malaysia from palliative care nurses' perspectives. Journal of Clinical Nursing. 23 (12), 173-180.

https://doi.org/10.1111/jocn.12242

Keumhee, N., Juhee, L., Eunhee, C., \& Changoh, K. (2016). Factors Related to Emergency Department Healthcare Providers' Attitudes towards End-of-Life Care. The Korean Journal of Hospice and Palliative Care, 19(1), 11-25.

http://dx.doi.org/10.14475/kjhpc.2016.19.1.11

Pan, H, H., Shih, H, L., Wu, L, F., Hung, Y, C., Chu, C, M., \& Wang, K, Y. (2017). Path modeling of knowledge, attitude and practice toward palliative care consultation service among Taiwanese nursing staff: a cross-sectional study, BMC Palliative Care, 16(1), 42.

https://doi.org/10.1186/s12904-017-0228-6

Scott, D., Reid, J., Hudson, P., Martin, P., \& Porter, S. (2016). Health care professionals' experience, understanding and perception of need of advanced cancer patients with cachexia and their families: The benefits of a dedicated clinic. BMC Palliative Care. 15(100). https://doi.org/10.1186/s12904-016-0171-y

Tait, V., Megan, H., Linda, M., Dixon, J., Davis, J, M., \& Fernandez, R. (2015). Attitudes of Nonpalliative Care Nurse towards Palliative Care, International Journal of Palliative Care, 4691741-469174-6.

https://doi.org/10.1155/2015/469174

Wang, L. P., Li, Y. J., Yan, W. Z., \& Li, G. M. (2016). Development and Psychometric Testing Chinese Version of the Frommelt Attitude Toward Care of the Dying Scale, Form B in Nurses and Nursing Students. Journal of Cancer Education: The Official Journal of the American Association for Cancer Education, 31(1), 123130.

https://doi.org/10.1007/s13187-015-0810-7

Wright, M., Hamzah, E., Phungrassami, T., \& BausaClaudio A. (2008). Hospice and palliative care in
South-eastern Asia: a review of developments and challenges in Malaysia, Thailand and the Philippines. New York: Oxford University Press; 2010.

https://global.oup.com/academic/product/hos pice-and-palliative-care-in-southeast-asia9780199574964 ?cc=us\&lang=en\& $($ accessed 26 October 2020)

Yang, F, Min., Ye, Z, H., Tang, L, W., Xiang, W, L., Yan, L, J., et al. (2017). Factors associated with the attitudes of oncology nurses toward hospice care in China. Patient Preference and Adherence, 11, 853-860 https://doi.org/10.2147/PPA.S132093 
Table 1. Socio-demographic characteristics of participants $(n=217)$

\begin{tabular}{|c|c|}
\hline Characteristics & \\
\hline \multicolumn{2}{|l|}{ Gender, n (\%) } \\
\hline Male & $43(19.8)$ \\
\hline Female & $174(80.2)$ \\
\hline \multicolumn{2}{|l|}{ Working place, $\mathrm{n}(\%)$} \\
\hline Hospital & $166(76.5)$ \\
\hline Nursing homes & $19(8.8)$ \\
\hline Primary health center & $32(14.7)$ \\
\hline \multicolumn{2}{|l|}{ Institution, n (\%) } \\
\hline Governmental hospital & 42 (19.4) \\
\hline Non-governmental hospital & $124(57.1)$ \\
\hline Nursing homes & $19(8.8)$ \\
\hline Primary health center & $32(14.7)$ \\
\hline \multicolumn{2}{|l|}{ Religion } \\
\hline Islam & $207(95.4)$ \\
\hline Protestant & $3(1.4)$ \\
\hline Catholic & $6(2.8)$ \\
\hline Hindu & $1(0.5)$ \\
\hline \multicolumn{2}{|l|}{ Highest level of education, $n(\%)$} \\
\hline Master's degree & $3(1.4)$ \\
\hline Bachelor's degree & $61(28.1)$ \\
\hline Vocational school & $153(70.5)$ \\
\hline \multicolumn{2}{|l|}{ Working experience, $\mathrm{n}(\%)$} \\
\hline Less than 1 years & $7(3.2)$ \\
\hline $1-2$ years & $29(13.4)$ \\
\hline $2-3$ years & $25(11.5)$ \\
\hline 3-5 years & $29(13.4)$ \\
\hline $5-10$ years & $57(26.3)$ \\
\hline More than 10 years & $70(32.3)$ \\
\hline \multicolumn{2}{|l|}{ Home location, $\mathrm{n}(\%)$} \\
\hline Downtown & $17(7.8)$ \\
\hline Residential areas & $19(8.8)$ \\
\hline Countryside Villages & $153(70.5)$ \\
\hline Others & $28(12.9)$ \\
\hline \multicolumn{2}{|l|}{ Type of house, $n$ (\%) } \\
\hline Own house & $179(82.5)$ \\
\hline Rented house & $21(9.7)$ \\
\hline others & $17(7.8)$ \\
\hline \multicolumn{2}{|l|}{ Characteristics } \\
\hline Age, years mean (SD) & $32.52(7.37)$ \\
\hline Family member, mean (SD) & $3,94(1,52)$ \\
\hline
\end{tabular}

Table 2. The frequency distribution of nurses' attitudes towards care of the dying based on total FATCOD, family FATCOD and patient FATCOD ( $n=217)$

\begin{tabular}{lcc}
\hline Attitudes & Frequency & Percentage \\
\hline Total FATCOD & & \\
Favorable & 100 & 46.1 \\
attitude & 117 & 53.9 \\
$\quad \begin{array}{l}\text { Unfavorable } \\
\text { attitude }\end{array}$ & & \\
Family FATCOD & & \\
$\quad$ Favorable & 104 & 47.9 \\
attitude & 113 & 52.1 \\
Unfavorable & & \\
attitude & & \\
Patient FATCOD & & \\
Favorable & 111 & 51.2 \\
attitude & 106 & 48.8 \\
Unfavorable & & \\
attitude & & \\
\hline
\end{tabular}




\section{NUNRSINGG \\ PRACTICES}

Table 3. Descriptive statistic score of the Frommelt attitudes towards care of the dying (FATCOD) ( $n=217$ )

\begin{tabular}{lcc}
\hline Variables & Min-Max & Mean \pm SD \\
\hline Total FATCOD & $71-139$ & $111.29 \pm 9.44$ \\
Family FATCOD & $20-50$ & $39.85 \pm 4.12$ \\
Patient FATCOD & $50-93$ & $71.43 \pm 6.39$ \\
\hline
\end{tabular}

Table 4. Association between demographic characteristics of participants and attitudes towards death and dying $(n=217)$

\begin{tabular}{|c|c|c|c|c|c|c|c|}
\hline \multirow[t]{2}{*}{ Variable } & & \multicolumn{2}{|c|}{ Total FATCOD } & \multicolumn{2}{|c|}{ Patient FATCOD } & \multicolumn{2}{|c|}{ Family FATCOD } \\
\hline & & $\mathbf{F}$ & $p$ & $\mathbf{F}$ & $\mathbf{p}$ & $\mathbf{F}$ & $p$ \\
\hline Gender, n (\%) & & -1.45 & 0.146 & -1.59 & 0.113 & -0.79 & 0.426 \\
\hline Male & $43(19.8)$ & & & & & & \\
\hline Female & $174(80.2)$ & & & & & & \\
\hline Working place, $\mathrm{n}(\%)$ & & 0.11 & 0.911 & 0.75 & 0.452 & -0.92 & 0.360 \\
\hline Hospital & $166(76.5)$ & & & & & & \\
\hline Nursing homes & $19(8.8)$ & & & & & & \\
\hline Primary health center & $32(14.7)$ & & & & & & \\
\hline Institution, n (\%) & & -0.91 & 0,365 & -1.30 & 0.194 & -0.02 & 0.985 \\
\hline Governmental hospital & $42(19.4)$ & & & & & & \\
\hline Non-governmental hospital & $124(57.1)$ & & & & & & \\
\hline Nursing homes & $19(8.8)$ & & & & & & \\
\hline Primary health center & $32(14.7)$ & & & & & & \\
\hline Religion & & -0.49 & 0.618 & -0.80 & 0.422 & 0.10 & 0.917 \\
\hline Islam & $207(95.4)$ & & & & & & \\
\hline Protestant & $3(1.4)$ & & & & & & \\
\hline Catholic & $6(2.8)$ & & & & & & \\
\hline Hindu & $1(0.5)$ & & & & & & \\
\hline Highest level of education, $\mathrm{n}(\%)$ & & -0.89 & 0.372 & 0.17 & 0.862 & -2.34 & 0.020 \\
\hline Master's degree & $3(1.4)$ & & & & & & \\
\hline Bachelor's degree & $61(28.1)$ & & & & & & \\
\hline Vocational school & $153(70.5)$ & & & & & & \\
\hline Working experience, $\mathrm{n}(\%)$ & & 2.06 & 0.040 & 2.83 & 0.005 & 2.09 & 0.037 \\
\hline Less than 1 years & $7(3.2)$ & & & & & & \\
\hline $1-2$ years & $29(13.4)$ & & & & & & \\
\hline $2-3$ years & $25(11.5)$ & & & & & & \\
\hline 3-5 years & $29(13.4)$ & & & & & & \\
\hline $5-10$ years & $57(26.3)$ & & & & & & \\
\hline More than 10 years & $70(32.3)$ & & & & & & \\
\hline Home location, $\mathrm{n}(\%)$ & & 0.68 & 0.496 & 0.67 & 0.500 & 0.51 & 0.607 \\
\hline Downtown & $17(7.8)$ & & & & & & \\
\hline Residential areas & $19(8.8)$ & & & & & & \\
\hline Countryside Villages & $153(70.5)$ & & & & & & \\
\hline Others & $28(12.9)$ & & & & & & \\
\hline Type of house, $n(\%)$ & & -0.90 & 0.368 & -1.02 & 0.056 & 0.44 & 0.659 \\
\hline Own house & $179(82.5)$ & & & & & & \\
\hline Rented house & $21(9.7)$ & & & & & & \\
\hline others & $17(7.8)$ & & & & & & \\
\hline Age, years mean (SD) & $32.52(7.37)$ & 0.06 & 0.945 & -0.06 & 0.952 & 0.25 & 0.800 \\
\hline Family member, mean (SD) & $3,94(1,52)$ & 0.84 & 0.401 & 0.66 & 0.511 & 0.91 & 0.363 \\
\hline
\end{tabular}

